\title{
Labetalol, nebivolol, and propranolol relax human radial artery used as coronary bypass graft
}

\author{
Ozge Korkmaz, MD, ${ }^{\mathrm{a}}$ Bülent Saraç, MD, ${ }^{\mathrm{b}}$ Sabahattin Göksel, MD, ${ }^{\mathrm{a}}$ Sahin Yildirim, MD, \\ Ocal Berkan, MD, ${ }^{\mathrm{a}}$ and Ihsan Bagcivan, $\mathrm{MD}^{\mathrm{b}}$
}

\begin{abstract}
Objective: Beta-blockers are a heterogeneous class of agents that are used in the treatment of many cardiovascular diseases, especially hypertension and atherosclerosis, and that are commonly prescribed after cardiac surgery. In the present study, the aim is to investigate the vasorelaxant effects of some common beta-adrenoceptor blockers on the human radial artery in vitro, as well as their relaxation mechanisms.
\end{abstract}

\begin{abstract}
Methods: Radial artery rings sourced from human patients were mounted in an organ bath and tested for changes in isometric tension in relaxation response to labetalol, nebivolol, and propranolol in the presence and absence of NG-nitro-L-arginine methyl ester $\left(3 \times 10^{-5} \mathrm{~mol} / \mathrm{L}\right)$ and tetraethyl ammonium $\left(3 \times 10^{-4} \mathrm{~mol} / \mathrm{L}\right)$.

Results: The labetalol $\left(10^{-8}\right.$ to $\left.10^{-4} \mathrm{~mol} / \mathrm{L}\right)$, nebivolol $\left(10^{-8}\right.$ to $\left.10^{-4} \mathrm{~mol} / \mathrm{L}\right)$, and propranolol $\left(10^{-8}\right.$ to $10^{-4}$ $\mathrm{mol} / \mathrm{L}$ ) induced concentration-dependent relaxations on the radial artery rings, which had been precontracted with phenylephrine $\left(10^{-6} \mathrm{~mol} / \mathrm{L}\right)$. The relaxation response induced by labetalol in the isolated radial artery rings was significantly higher when compared with the nebivolol and propranolol samples $(P<.05)$. NG-nitro-L-arginine methyl ester significantly reduced the relaxation of nebivolol $(P<.05)$, and tetraethyl ammonium significantly reduced the relaxation of labetalol, nebivolol, and propranolol $(P<.05)$.

Conclusions: We speculated that the relaxant effect of labetalol, nebivolol, and propranolol was due partly to the $\mathrm{Ca}^{2+}$-activated $\mathrm{K}^{+}$channels. In addition, the relaxation induced by nebivolol was largely related with nitric oxide release. Nebivolol, and partly propranolol, may provide significant therapeutic benefit, but labetalol can be a good alternative for coronary artery bypass grafting with radial artery use. (J Thorac Cardiovasc Surg 2015;149:1036-40)
\end{abstract}

See related commentary on pages $1040-1$.

The radial artery (RA) is the most popular arterial graft after the left internal thoracic artery in both low- and high-risk patients undergoing coronary artery bypass grafting (CABG). ${ }^{1}$ Carpentier and colleagues ${ }^{2}$ were the first to introduce the RA graft for CABG in 1973; however, poor short-term results $(35 \%-50 \%$ graft occlusion rate) due to spasm and intimal hyperplasia resulted in the abandonment of the procedure. ${ }^{3,4}$ Nevertheless, in 1992, Acar and colleagues ${ }^{5}$ discovered incidentally that previous RA grafts were free from progressive graft disease and reintroduced the RA as a conduit for CABG because of its good length, suitable inner diameter, ease of handling, and minimal donor site discomfort. ${ }^{5}$ Several studies show

From the Departments of Cardiovascular Surgery ${ }^{\mathrm{a}}$ and Pharmacology, ${ }^{\mathrm{b}}$ Cumhuriyet University School of Medicine, Sivas, Turkey.

Disclosures: Authors have nothing to disclose with regard to commercial support.

Received for publication Nov 10, 2014; revisions received Dec 18, 2014; accepted for publication Jan 2, 2015; available ahead of print March 6, 2015.

Address for reprints: Ozge Korkmaz, MD, Department of Cardiovascular Surgery, Cumhuriyet University School of Medicine, 58140 Sivas, Turkey (E-mail: ozgekorkmaz73@hotmail.com).

$0022-5223 / \$ 36.00$

Copyright (c) 2015 by The American Association for Thoracic Surgery

http://dx.doi.org/10.1016/j.jtcvs.2015.01.006 mid- and long-term patency rates of $83 \%$ to $96.8 \%$ after RA harvesting, ${ }^{6-8}$ whereas vasorelaxant drugs used post-CABG may prevent postsurgical problems (eg, graft occlusion and vasospasm) and patency rates in RA grafts.

Beta-blockers are a heterogeneous class of agents that are used in the treatment of many cardiovascular diseases, especially hypertension and atherosclerosis, ${ }^{9}$ although different blockers may have different effects on blood vessels according to their individual properties. ${ }^{10}$ Beta-blockers are commonly prescribed after cardiac surgery and CABG. Chan and colleagues ${ }^{11}$ found that beta-blockers were prescribed to $83 \%$ of patients at hospital discharge who had undergone nontransplant cardiac surgery.

Because patients who undergo CABG with RA use are candidates to use beta-blockers, in the present study, the aim is to investigate the vasorelaxant effects of some commonly used beta-adrenoceptor blockers (labetalol, nebivolol, and propranolol) on the human RA in vitro, as well as their relaxation mechanisms, and to compare their effectiveness in terms of vasorelaxation in RA.

\section{MATERIALS AND METHODS}

Human RA segments were removed from 20 patients undergoing selective CABG surgery using procedures for the handling of human tissue approved by the Human Ethics Committee of Cumhuriyet University. Written informed consent was obtained from all patients before surgery. Specimens of 1 to $2 \mathrm{~cm}$ 

Abbreviations and Acronyms
$\mathrm{CABG}=$ coronary artery bypass grafting
Emax = maximum relaxant effect
L-NAME $=$ NG-nitro-L-arginine methyl ester
$\mathrm{NO}=$ nitric oxide
RA $\quad$ radial artery
TEA $\quad=$ tetraethyl ammonium

in length were excised from the distal or proximal end of the RA and placed in a Krebs-Henseleit solution. All connective tissues were dissected, and the vessel was divided into rings of 3 to $4 \mathrm{~mm}$ in length.

The RA rings (4 rings from each artery) were suspended in a $10 \mathrm{~mL}$ organ bath containing a Krebs-Henseleit solution of the following composition: $\mathrm{NaCl}, 118.4 \mathrm{mmol} / \mathrm{L} ; \mathrm{KCl}, 4.7 \mathrm{mmol} / \mathrm{L} ; \mathrm{CaCl}_{2}, 2.5 \mathrm{mmol} / \mathrm{L}$; $\mathrm{MgSO}_{4}, 1.3 \mathrm{mmol} / \mathrm{L} ; \mathrm{KH}_{2} \mathrm{PO}_{4}, 1.2 \mathrm{mmol} / \mathrm{L} ; \mathrm{NaHCO}_{3}, 5.0 \mathrm{mmol} / \mathrm{L}$; and glucose, $11.0 \mathrm{mmol} / \mathrm{L}$. The solution was aerated continuously with a gas mixture of $95 \% \mathrm{O}_{2}$ and $5 \% \mathrm{CO}_{2}$, and maintained at $37^{\circ} \mathrm{C}$. The RA rings were equilibrated for 2 hours with a resting tension of $2 g$, determined to be the optimal resting tension in preliminary length-tension experiments. Isometric tensions were measured using a Grass FT-03 force-displacement transducer and recorded on a 4-channel Grass polygraph (model $79 \mathrm{E}$; Grass Instruments, Quincy, Mass). ${ }^{12}$ After a 2-hour equilibration period, the tissues were precontracted with a submaximal concentration of phenylephrine $\left(10^{-6} \mathrm{~mol} / \mathrm{L}\right)$. After phenylephrine-induced submaximal contraction had reached a plateau, the concentration-response relationships for beta-blockers (labetalol $\left[10^{-8}\right.$ to $\left.10^{-4} \mathrm{~mol} / \mathrm{L}\right]$, nebivolol $\left[10^{-8}\right.$ to $10^{-4}$ $\mathrm{mol} / \mathrm{L}]$, and propranolol $\left[10^{-8}\right.$ to $\left.10^{-4} \mathrm{~mol} / \mathrm{L}\right]$ ) were obtained by adding each agent to the bath cumulatively. At the end of the experiment, papaverine $\left(10^{-4} \mathrm{~mol} / \mathrm{L}\right)$ was added to the organ bath to obtain maximal relaxation. The relaxations of labetalol, nebivolol, and propranolol were taken again in the presence of NG-nitro-L-arginine methyl ester (L-NAME, $3 \times 10^{-5} \mathrm{~mol} / \mathrm{L}$, nonspecific inhibitor of nitric oxide [NO] synthase) and tetraethyl ammonium (TEA $3 \times 10^{-4} \mathrm{~mol} / \mathrm{L}, \mathrm{Ca}^{2+}$-activated $\mathrm{K}^{+}$channel blocker). L-NAME and TEA were added to the organ bath 15 minutes before the precontraction of phenylephrine. The relaxation responses induced by labetalol, nebivolol, and propranolol were expressed as a percentage of precontraction by phenylephrine. The maximum relaxant effect (Emax) and concentrations of labetalol, nebivolol, and propranolol, producing $50 \%$ of the Emax (EC50) were calculated for each concentration-response curve. The pEC50 (pD2 [the negative logarithm to base 10 of the EC50]) was calculated as the negative logarithm to base 10 of the EC50 for statistical analysis. Experimental values are presented as mean \pm the standard error of the mean and were analyzed through repeated measures of the analysis of variance with a Newman-Keuls test and a $t$ test when appropriate. Value $\mathrm{n}$ represents the number of patients. All statistical analyses were performed using the Statistical Package for the Social Sciences version 14 (SPSS Inc, Chicago, Ill). The chemicals used in the current experiments were papaverine hydrochloride, LNAME, TEA chloride, phenylephrine hydrochloride, labetalol hydrochloride, nebivolol hydrochloride, and propranolol hydrochloride from Sigma (St Louis, Mo). The chemicals were dissolved in distilled water and then diluted with distilled water for the preparation of decreasing concentrations. The drug-containing solutions were prepared on the day of the experiments.

\section{RESULTS}

Segments of RA were obtained from 20 patients (14 male and 6 female), with an average age of $57.95 \pm 6.43$ years. The patient characteristics, risk factors, and medications are presented in Table 1. Labetalol $\left(10^{-8}\right.$ to $10^{-4} \mathrm{~mol} / \mathrm{L}$, $\mathrm{n}=20)$, nebivolol $\left(10^{-8}\right.$ to $\left.10^{-4} \mathrm{~mol} / \mathrm{L}, \mathrm{n}=20\right)$, and propranolol $\left(10^{-8}\right.$ to $\left.10^{-4} \mathrm{~mol} / \mathrm{L}, \mathrm{n}=20\right)$ induced concentration-dependent relaxations on the RA rings precontracted with phenylephrine $\left(10^{-6} \mathrm{~mol} / \mathrm{L}\right)$. The relaxation responses of all 3 beta-blockers were taken in the presence and absence of L-NAME $\left(3 \times 10^{-5} \mathrm{~mol} / \mathrm{L}\right)$ and TEA $\left(3 \times 10^{-4} \mathrm{~mol} / \mathrm{L}\right)$. The relaxation responses induced in isolated RA rings labetalol were significantly higher than those of nebivolol and propranolol $(P<.05$, Figure 1$)$, and the relaxation responses induced by nebivolol were significantly higher than those in the propranolol sample $(P<.05$, Figure 1$)$. The relaxation responses induced by all drugs in the isolated RA rings reached statistical significance beginning at $10^{-7} \mathrm{~mol} / \mathrm{L}$ concentration $(P<.05$, Figure 1). At the end of the experiment, papaverine caused the complete relaxation of the submaximal phenylephrine contraction. Table 2 presents the pD2 and Emax values of labetalol, nebivolol, and propranolol in RA rings precontracted by phenylephrine. L-NAME significantly reduced the relaxation of nebivolol $(P<.05$, Figure 1$)$, whereas the change in relaxation with labetalol and propranolol was not significant $(P>.05$, Figures 2 and 3$)$. The LNAME reduction of the relaxation of nebivolol was significantly higher than TEA $(P<.05$, Figure 4$)$, which reduced significantly the relaxation of labetalol, nebivolol, and propranolol $(P<.05$, Figures 1,2 , and 4$)$.

\section{DISCUSSION}

In CABG surgery, arterial grafts have been used with increasing frequency because the long-term patency is expected to be superior to that seen with venous grafts. In recent years the RA has been reintroduced for CABG. ${ }^{12}$

Beta-blockers are the most common form of medication in the treatment of hypertension and various cardiovascular diseases. ${ }^{9}$ Recently, the role of beta-blockers in reducing perioperative mortality has been challenged for CABG, leading to their short- and long-term administration being recommended for patients undergoing $\mathrm{CABG} .{ }^{13,14}$ Chan and colleagues ${ }^{11}$ found that those patients who were discharged and prescribed beta-blockers after cardiac surgery exhibited a substantially lower rate of death at 1 year. Sarikaya and colleagues ${ }^{15}$ suggest that nebivolol might be considered a good choice in hypertensive patients undergoing cardiac surgery, given its prevention of perioperative myocardial hypoperfusion, which increases early morbidity and mortality. Bayar and colleagues ${ }^{16}$ suggest that nebivolol may be safer and preferable to diminish graft spasm in patients undergoing CABG surgery because of the NO-mediated vasodilation effect. ${ }^{16}$ Vasorelaxant beta-blockers used post-CABG may have beneficial effects on postsurgical problems (graft occlusion and vasospasm) and the short-, mid-, and long-term patency rates of RA grafts. 
TABLE 1. Patient characteristics, risk factors, and medication in radial artery segments obtained from 20 patients

\begin{tabular}{lcc}
\hline & pD2 & Emax \\
\hline Labetalol & $6.06 \pm 0.06$ & $93.8 \pm 3.0$ \\
L-NAME + labetalol & $6.02 \pm 0.08$ & $89.6 \pm 3.6$ \\
TEA + labetalol & $5.96 \pm 0.10$ & $67.8 \pm 4.0$ \\
Nebivolol & $5.88 \pm 0.08$ & $69.4 \pm 4.8$ \\
L-NAME + nebivolol & $5.96 \pm 0.10$ & $31.4 \pm 4.7$ \\
TEA + nebivolol & $6.01 \pm 0.08$ & $45.6 \pm 4.0$ \\
Propranolol & $6.02 \pm 0.10$ & $51.8 \pm 4.8$ \\
L-NAME + propranolol & $5.92 \pm 0.08$ & $44.0 \pm 4.4$ \\
TEA + propranolol & $6.12 \pm 0.07$ & $25.4 \pm 4.0$ \\
\hline E
\end{tabular}

Emax, Maximum relaxant effect; $L-N A M E$, NG-nitro-L-arginine methyl ester; $p D 2$, the negative logarithm to base 10 of the EC50; TEA, tetraethyl ammonium.

Previous studies have shown that some beta-blockers have relaxant effects in various vascular tissues in vitro. For example, Floreani and colleagues ${ }^{17}$ have shown that a nonconventional partial agonist of beta-1 adrenoceptors carteolol relaxed phenylephrine-constricted rat aorta through antagonism at alfa-1 adrenoceptors. In addition, there are many studies investigating nebivolol relaxation in different tissues. ${ }^{9,18,19}$ In this study, the intention is to investigate the vasorelaxant effects and the relaxation mechanisms of commonly used beta-adrenoceptor blockers (labetalol, nebivolol, and propranolol) on the human RA in vitro to determine the suitability of these beta-blockers in patients undergoing CABG with RA.

Labetalol is a selective beta-blocker and a postsynaptic alfa-1 blocking agent ${ }^{20}$ that is reported to possess some intrinsic sympathomimetic and membrane-stabilizing properties. In addition, it contains selective alfa-1-blocking properties that decrease peripheral vascular resistance. ${ }^{21}$ Doqqrell $^{22}$ demonstrated the relaxant and beta-2 adrenoceptor blockage activities of labetalol on an isolated

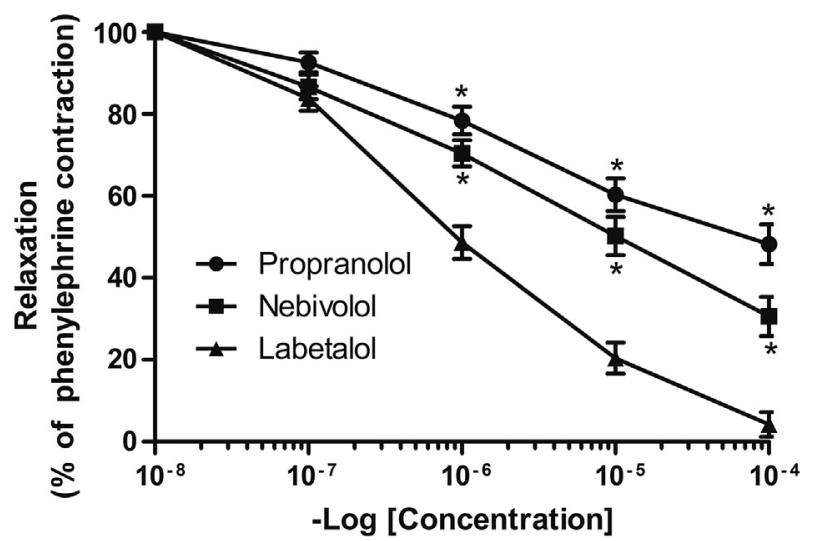

FIGURE 1. Relaxation responses induced by propranolol, nebivolol, and labetalol on human RA. Relaxations are expressed as percentage of phenylephrine $\left(10^{-6} \mathrm{~mol} / \mathrm{L}\right)$-induced precontraction and shown as mean \pm standard error of the mean (SEM). *Statistically different from labetalol relaxations $(P<.05)$.
TABLE 2. pD2 and maximum relaxant effect values of labetalol, nebivolol, and propranolol in radial artery rings precontracted by phenylephrine

\begin{tabular}{lc}
\hline Patient characteristics and risk factors & \\
Age $(\mathrm{y})$ & $57.95 \pm 6.43$ \\
Male, $\mathrm{n}(\%)$ & $14 / 6(70.0 / 30.0)$ \\
Smoker, $\mathrm{n}(\%)$ & $9(45.0)$ \\
Hypertensive patients, $\mathrm{n}(\%)$ & $12(60.0)$ \\
Diabetic patients, $\mathrm{n}(\%)$ & $6(30.0)$ \\
Hyperlipidemia, $\mathrm{n}(\%)$ & $8(40.0)$ \\
Total cholesterol (mg/dL) & $191.40 \pm 50.48$ \\
TG (mg/dL) & $169.52 \pm 41.57$ \\
HDL (mg/dL) & $43.73 \pm 12.92$ \\
LDL (mg/dL) & $122.12 \pm 38.73$ \\
VLDL (mg/dL) & $32.76 \pm 18.72$ \\
Medication & \\
Nitrates, $\mathrm{n}(\%)$ & $12(60.0)$ \\
Statins, $\mathrm{n}(\%)$ & $8(40.0)$ \\
ACE inhibitors, $\mathrm{n}(\%)$ & $13(65.0)$ \\
Ca ${ }^{2+}$ antagonists, $\mathrm{n}(\%)$ & $6(30.0)$ \\
Beta-blockers, $\mathrm{n}(\%)$ & $13(65.0)$ \\
Oral antidiabetics, $\mathrm{n}(\%)$ & $5(25.0)$ \\
Insulin, $\mathrm{n}(\%)$ & $1(5.0)$ \\
Aspirin, $\mathrm{n}(\%)$ & $13(65.0)$ \\
\hline ACE
\end{tabular}

$A C E$, Angiotensin-converting enzyme; $H D L$, high-density lipoprotein; $L D L$, lowdensity lipoprotein; $T G$, triglyceride; $V L D L$, very low-density lipoprotein.

rat aorta. Likewise, Monma and colleagues ${ }^{23}$ found that labetalol decreased arterial blood pressure in vivo. In the present study, labetalol completely relaxed the human RA rings precontracted with phenylephrine. Labetalol relaxations did not change significantly in the presence of L-NAME; however, TEA reduced the relaxation of labetalol significantly. It can be speculated that this relaxant effect of labetalol is not related with NO release, but partly through $\mathrm{Ca}^{2+}$-activated $\mathrm{K}^{+}$channels.

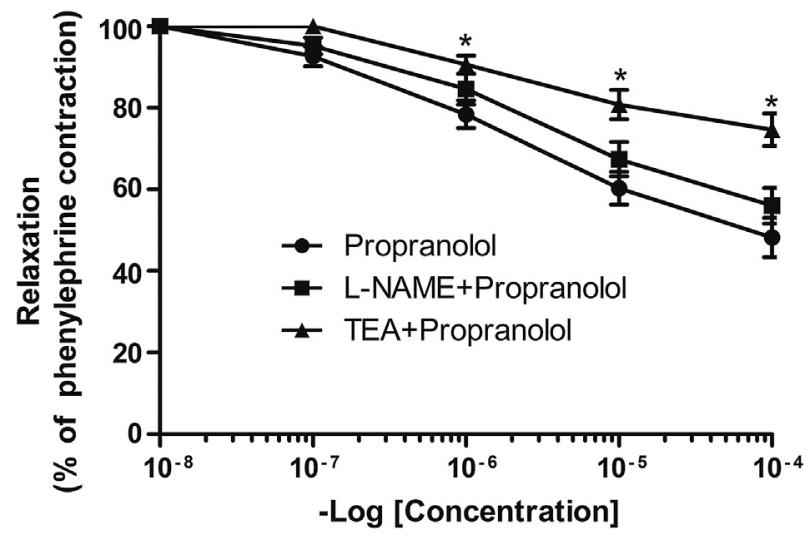

FIGURE 2. Relaxation responses induced by propranolol in the presence and absence of L-NAME $\left(3 \times 10^{-5} \mathrm{~mol} / \mathrm{L}\right)$ and TEA $\left(3 \times 10^{-4} \mathrm{~mol} / \mathrm{L}\right)$ on human RA. Relaxations are expressed as percentage of phenylephrine $\left(10^{-6} \mathrm{~mol} / \mathrm{L}\right)$-induced precontraction and shown as mean $\pm \mathrm{SEM}$. *Statistically different from propranolol relaxations $(P<.05) . L-N A M E$, NG-nitro-L-arginine methyl ester; TEA, tetraethyl ammonium. 


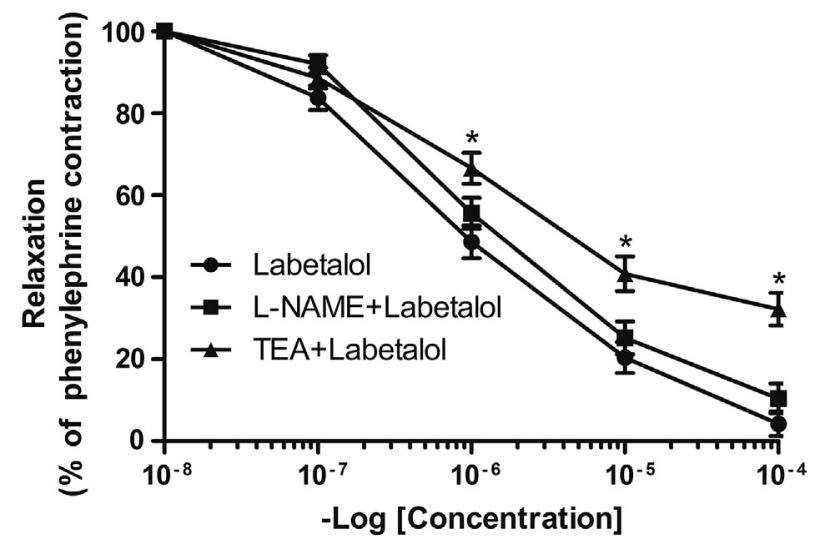

FIGURE 3. Relaxation responses induced by labetalol in the presence and absence of L-NAME $\left(3 \times 10^{-5} \mathrm{~mol} / \mathrm{L}\right)$ and TEA $\left(3 \times 10^{-4} \mathrm{~mol} / \mathrm{L}\right)$ on human RA. Relaxations are expressed as percentage of phenylephrine $\left(10^{-6} \mathrm{~mol} / \mathrm{L}\right)$-induced precontraction and shown as mean $\pm \mathrm{SEM}$. *Statistically different from labetalol relaxations $(P<.05)$. L-NAME, NG-nitro-L-arginine methyl ester; TEA, tetraethyl ammonium.

Nebivolol is a novel, third-generation, cardioselective beta-1 adrenergic receptor blocker with endotheliumdependent vasodilation properties. ${ }^{18}$ The vasodilator properties of nebivolol are useful in the management of essential hypertension involving vascular endothelium. ${ }^{24}$ It has been reported that the vasodilator properties of nebivolol are mediated by endothelium-derived $\mathrm{NO}^{25,26}$ Additional studies revealed that nebivolol may cause vasorelaxation through the activation of the endothelial inositol phosphate metabolism, the mobilization of intracellular calcium, and the consequent activation of endothelial NO synthase. ${ }^{26}$ In our study, nebivolol relaxed the human RA rings precontracted with phenylephrine,

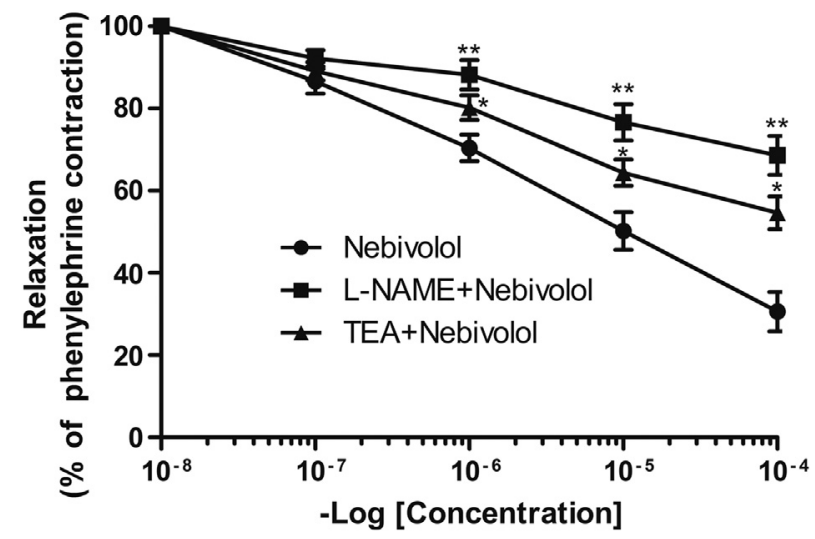

FIGURE 4. Relaxation responses induced by nebivolol in the presence and absence of L-NAME $\left(3 \times 10^{-5} \mathrm{~mol} / \mathrm{L}\right)$ and TEA $\left(3 \times 10^{-4} \mathrm{~mol} / \mathrm{L}\right)$ on human RA. Relaxations are expressed as percentage of phenylephrine $\left(10^{-6} \mathrm{~mol} / \mathrm{L}\right)$-induced precontraction and shown as mean $\pm \mathrm{SEM}$. *Statistically different from nebivolol relaxations $(P<.05)$. **Statistically different from nebivolol relaxations and TEA + nebivolol relaxations $(P<.05) . L-N A M E$, NG-nitro-L-arginine methyl ester; TEA, tetraethyl ammonium. and these relaxations were reduced significantly in the presence of L-NAME, but only partly reduced in the presence of TEA. It can be speculated that these relaxant effects of nebivolol are largely related to NO release and partly through $\mathrm{Ca}^{2+}$-activated $\mathrm{K}^{+}$channels.

Priviero and colleagues ${ }^{27}$ have demonstrated the vasorelaxant effects of propranolol in the aorta and mesenteric artery of rats via NO and a calcium entry blockade. It was found that propranolol has relaxation effects on human RA rings precontracted by phenylephrine, although to a lesser degree than labetalol and nebivolol. The propranolol relaxations did not change significantly in the presence of L-NAME, although TEA reduced the relaxation of propranolol significantly. It can be speculated that this relaxant effect of propranolol may be related with the opening of $\mathrm{Ca}^{2+}$-activated $\mathrm{K}^{+}$channels.

\section{CONCLUSIONS}

This study has revealed that labetalol, nebivolol, and propranolol have concentration-dependent relaxant properties in RA rings. Although propranolol is a clinically more preferred agent than labetalol and nebivolol, the relaxation response induced by labetalol and nebivolol in the isolated RA rings were significantly higher than that of propranolol. TEA reduced significantly the relaxation of labetalol, nebivolol, and propranolol, whereas L-NAME reduced only the relaxation caused by nebivolol to any significant level. It can speculated that these relaxant effects of labetalol, nebivolol, and propranolol are partly mediated through $\mathrm{Ca}^{2+}$-activated $\mathrm{K}^{+}$channels and that nebivolol relaxation is commonly related to $\mathrm{NO}$ release.

Labetalol, nebivolol, and partly propranolol may offer significant therapeutic benefit after RA grafts for CABG. The vasorelaxant effect of labetalol especially is more potent than the other 2 agents. According to our findings, labetalol can be a good alternative for CABG with RA use, but these findings should be supported by further controlled clinical studies.

\section{References}

1. Baikoussis NG, Papakonstantinou NA, Apostolakis E. Radial artery as graft for coronary artery bypass surgery: advantages and disadvantages for its usage focused on structural and biological characteristics. J Cardiol. 2014;63:321-8.

2. Carpentier A, Guermonprez JL, Deloche A, Frechette C, DuBost C. The aorta-tocoronary artery radial bypass graft: a technique avoiding pathological changes in grafts. Ann Thorac Surg. 1973;16:111-21.

3. Geha AS, Krone RJ, McCormick JR, Baue AE. Selection of coronary bypass. Anatomic, physiological, and angiographic considerations of vein and mammary artery grafts. J Thorac Cardiovasc Surg. 1975;70:414-31.

4. Curtis JJ, Stoney WS, Alford WC Jr, Burrus GR, Thomas CS Jr. Intimal hyperplasia. A cause of radial artery aortocoronary bypass graft failure. Ann Thorac Surg. 1975;20:628-35.

5. Acar C, Jebara VA, Portoghese M, Beyssen B, Pagny JY, Grare P, et al. Revival of the radial artery for coronary artery bypass-grafting. Ann Thorac Surg. 1992;54: 652-60.

6. Acar C, Ramsheyi A, Pagny JY, Jebara V, Barrier P, Fabiani JN, et al. The radial artery for coronary artery bypass grafting: clinical and angiographic results a five years. J Thorac Cardiovasc Surg. 1998;116:981-9. 
7. Tatoulis J, Buxton BF, Fuller JA. Bilateral radial artery grafts in coronary reconstruction: technique and early results in 261 patients. Ann Thorac Surg. 1998;66:714-9.

8. Buxton BF, Fuller JA, Tatoulis J. Evolution of complete arterial grafting. For coronary artery disease. Tex Heart Inst J. 1998;25:17-23.

9. Larochelle P, Tobe SW, Lacourcière Y. $\beta$-Blockers in hypertension: studies and meta-analyses over the years. Can J Cardiol. 2014;30:16-22.

10. Sandeep G, Harold MW. Nebivolol: a highly selective $\beta 1$-adrenergic receptor blocker that causes vasodilation by increasing nitric oxide. Cardiovasc Ther 2008:26:189-202.

11. Chan AY, McAlister FA, Norris CM, Johnstone D, Bakal JA, Ross DB; Alberta Provincial Program for Outcome Assessment in Coronary Heart Disease (APPROACH) Investigators. Effect of beta-blocker use on outcomes after discharge in patients who underwent cardiac surgery. J Thorac Cardiovasc Surg. 2010;140:182-7.

12. He GW, Yang CQ. Comparison of the vasorelaxant effect of nitroprusside and nitroglycerin in the human radial artery in vitro. Br J Clin Pharmacol. 1999; 48:99-104

13. Kertai MD, Esper SA, Akushevich I, Voora D, Ginsburg GS, Stafford-Smith M, et al; Cardiothoracic Anesthesia Research Endeavors (CARE) Group. Preoperative CYP2D6 metabolism-dependent $\beta$-blocker use and mortality after coronary artery bypass grafting surgery. J Thorac Cardiovasc Surg. 2014;147:1368-75.

14. Angeloni E, Melina G, Roscitano A, Refice S, Capuano F, Lechiancole A, et al. $\beta$-Blockers improve survival of patients with chronic obstructive pulmonary disease after coronary artery bypass grafting. Ann Thorac Surg. 2013;95:525-31.

15. Sarikaya S, Onk A, Boztosun B, Kocabay G, Sahin M, Fedakar A, et al. The effect of nebivolol on internal mammary artery blood flow during coronary artery bypass graft surgery. Perfusion. 2013;29:315-20.

16. Bayar E, Ilhan G, Furat C, Atik C, Arslanoglu Y, Kuran C, et al. The effect of different $\beta$-blockers on vascular graft nitric oxide levels: comparison of nebivolol versus metoprolol. Eur J Vasc Endovasc Surg. 2014;47:204-8.

17. Floreani M, Quintieri L, Varani K, Dorigo MT, Dorigo P. Carteolol, a non-conventional partial agonist of $\beta 1$-adrenoceptors, relaxes phenylephrine- constricted rat aorta through antagonism at $\alpha 1$-adrenoceptors. Eur J Pharmacol. 2008:590:269-75.

18. Pullen C, Coulson FR, Fenning A. Effects of resveratrol and nebivolol on isolated vascular and cardiac tissues from young rats. Adv Pharmacol Sci. 2014;2014 20386.

19. Howlett JG. Nebivolol: vasodilatator properties and evidence for relevance in treatment of cardiovascular disease. Can J Cardiol. 2014;30:29-37.

20. Elatrous S, Nouira S, Ouanes Besbes L, Marghli S, Boussarssar M, Sakkouhi M, et al. Short-term treatment of severe hypertension of pregnancy: prospective comparison of nicardipine and labetalol. Intensive Care Med. 2002;28:1281-6.

21. Belal F, Al-Shaboury S, Al-Tamra AS. Spectrophotometric determination of labetalol in pharmaceutical preparations and spiked human urine. Farmaco. 2003;58:293-9.

22. Doqqrell SA. Relaxant and beta 2-adrenoceptor blocking activities of labetalol, dilevalol, amosulalol and KF-4317 on the rat isolated aorta. J Pharm Pharmacol. $1988 ; 40: 812-5$.

23. Monma Y, Okuoka Y, Kameda H, Ichihara K, Abibo Y, Tanabe T. [Effects of labetalol on the circulatory system (author's transl)]. Nihon Yahuriqaku Zasshi. 1980;76:239-54.

24. Georgescu A, Pluteanu F, Flonta ML, Badila E, Dorobantu M, Popov D. The cellular mechanisms involved in the vasodilator effect of nebivolol on the renal artery. Eur J Pharmacol. 2005;508:159-66.

25. Cockcroft JR, Chowienczyk PJ, Brett SE, Chen CP, Dupont AG, Van Nueten L, et al. Nebivolol vasodilates human forearm vasculature: evidence for an L- arginine/NO-dependent mechanism. J Pharmacol Exp Ther. 1995;274:1067-71.

26. Parenti A, Filippi S, Amerini S, Granger HJ, Fazzini A, Ledda F. Inositol phosphate metabolism and nitric-oxide synthase activity in endothelial cells are involved in the vasorelaxant activity of nebivolol. J Pharmacol Exp Ther. 2000;292:698-703.

27. Priviero FB, Teixeira CE, Toque HA, Claudino MA, Webb RC, De Nucci G, et al. Vasorelaxant effects of propranolol in rat aorta and mesenteric artery: a role for nitric oxide and calcium entry blockade. Clin Exp Pharmacol Physiol. 2006;33: 448-55.

\title{
EDITORIAL COMMENTARY
}

\section{To block or not to block? That is the question}

\author{
Alden H. Harken, MD
}

See related article on pages 1036-40.

In 1948, a pharmacologist at the Medical College of Georgia identified the adrenergic family of signaling systems. Shortly thereafter, he distinguished $\alpha$ - and $\beta$-adrenergic receptor

From the Department of Surgery, University of California, San Francisco-East Bay, Oakland, Calif.

Disclosures: Author has nothing to disclose with regard to commercial support.

Received for publication Jan 12, 2015; accepted for publication Jan 14, 2015; available ahead of print Feb 7, 2015.

Address for reprints: Alden H. Harken, MD, Department of Surgery, University of California, San Francisco-East Bay, 1411 E 31st St, QIC 22134, Oakland, CA 94602 (E-mail: alden.harken@ucsfmedctr.org).

J Thorac Cardiovasc Surg 2015;149:1040-1

$0022-5223 / \$ 36.00$

Copyright (c) 2015 by The American Association for Thoracic Surgery

http://dx.doi.org/10.1016/j.jtcvs.2015.01.023 sites. The formidable significance of this revolutionary series of discoveries has weathered a stormy history of investigative turmoil. In a beautifully designed clinical study, Mangano and colleagues ${ }^{1}$ recorded a decrease in late mortality in noncardiac surgical patients treated with $\beta$-blockers; however, the survival benefit appeared only long after the medication had been discontinued. Lindenauer and colleagues ${ }^{2}$ conducted a huge retrospective study of perioperative $\beta$ blocker therapy; however, low-risk patients were included in the $\beta$-blocker group only after they had already had a cardiovascular event. Poldermans and coworkers ${ }^{3}$ reported a dramatic reduction in mortality with perioperative $\beta$ blockers for high-risk vascular patients; however, this work has been saddled with allegations of fraud. Finally, the Perioperative Ischemic Evaluation Study (POISE) group ${ }^{4}$ published their disappointing experience when they prescribed as much as 8 times the recommended starting dose to 